\title{
1 Systematic review of wastewater surveillance of antimicrobial resistance in
}

\section{2 human populations}

3 Chau KK $K^{1}$, Barker $\mathrm{L}^{1}$, Budgell EP ${ }^{1}$, Vihta $\mathrm{KD}^{1}$, Sims $\mathrm{N}^{2}$, Kasprzyk-Hordern $\mathrm{B}^{2}$, Harriss $\mathrm{E}^{3}$, Crook

$4 \quad \mathrm{DW}^{1,4}$, Read $\mathrm{DS}^{5}$, Walker $\mathrm{AS}^{1,6}$, Stoesser $\mathrm{N}^{1,4}$

6 Affiliations

$7 \quad{ }^{1}$ Nuffield Department of Medicine, John Radcliffe Hospital, Oxford OX3 9DU

8 2Department of Chemistry, Faculty of Science, University of Bath, Bath BA2 7AY

$9 \quad{ }^{3}$ Bodleian Healthcare Libraries, University of Oxford, Oxford OX3 9DU

$10{ }^{4}$ Department of Microbiology/infectious diseases, Oxford University Hospitals NHS

11 Foundation Trust, John Radcliffe Hospital, Oxford OX3 9DU

${ }^{5}$ UK Centre for Ecology \& Hydrology, Wallingford OX10 8BB

${ }^{6}$ NIHR Oxford Biomedical Research Centre, Oxford OX4 2PG

14

Corresponding author:

Kevin K. Chau, Nuffield Department of Medicine, University of Oxford, John Radcliffe

17 Hospital, Headley Way, Headington, OX3 9DU

e-mail: kevin.chau@ndm.ox.ac.uk 
19

\section{Abstract}

We systematically reviewed studies using wastewater for AMR surveillance in human populations, to determine: (i) the strength of the evidence for a wastewater-human AMR association, and (ii) methodological approaches which optimised identifying such an association, and which could be recommended as standard. We used Lin's concordance correlation coefficient (CCC) to quantify agreement between AMR prevalence in wastewater and human compartments, and logistic regression to identify study features (e.g. sampling methods) associated with high-agreement (defined as wastewater-human AMR prevalences within $\pm 10 \%$ ).

Of 8,867 records and 232 full-text methods reviewed, 29 studies were included. AMR prevalence data was extractable from 20 studies conducting phenotypic-only ( $n=11)$, genotypic-only $(n=1)$ or combined ( $n=8)$ AMR detection. Overall wastewater-human AMR concordance was reasonably high for both phenotypic ( $\mathrm{CCC}=0.81[95 \% \mathrm{Cl} 0.74-0.87])$ and genotypic comparisons ( $\mathrm{CCC}=0.88(95 \% \mathrm{Cl}$ 0.85-0.91)) despite diverse speciesphenotypes/genotypes and study design. Logistic regression was limited by inconsistent reporting of study features, and limited sample size; no significant relationships between study features and high wastewater-human AMR agreement were identified. Based on descriptive synthesis, composite/flow-proportional sampling of wastewater influent, longitudinal sampling $>12$ months, and time/location-matched comparisons generally had higher-agreement.

Further research and clear and consistent reporting of study methods is required to confirm optimal practice. 
41

42

\section{Introduction}

Antimicrobial resistance (AMR) is a significant threat to global health (O'Neill, 2016) and poses major challenges in treating infectious diseases. AMR is a multi-faceted problem compounded by diverse drivers facilitating emergence and spread. AMR surveillance is therefore critical to understanding trends, monitoring interventions and developing empiric treatment guidelines, as prioritised in the World Health Organisation's global AMR action plan (WHO, 2019). Large networks dedicated to sharing continental/global AMR data have been established to meet this need, including the European Antimicrobial Resistance Surveillance Network (EARS-Net) and the Global Antimicrobial Resistance Surveillance System (GLASS). However, current surveillance methods are limited by the reliance on individual-level sampling, which is often affected by selection bias towards healthcare-associated settings (WHO, 2018). For example, both EARS-Net and GLASS focus on AMR in clinical specimens from hospitalised patients; this however does not reliably capture AMR prevalence in commensal organisms, thought to silently constitute most of the true AMR burden (Fahrenfeld and Bisceglia, 2016; Hay et al., 2018; Hendriksen et al., 2019b). Additionally, reliance on routine clinical microbiology results often restricts data collection to a limited subset of culturable species, and focuses predominantly on susceptibility phenotypes with limited genotyping. This lack of genotyping hampers the surveillance of high-risk AMR-associated clones and the horizontal transfer of AMR determinants (Tacconelli et al., 2018).

Wastewater-based AMR surveillance has the potential to avoid biases in current surveillance methods by using wastewater to simultaneously sample both healthcare- and communityassociated populations (Newton et al., 2015). The approach has already been successful in 
illicit drug monitoring (González-Mariño, Baz-Lomba et al. 2020) and pathogen (particularly enterovirus) surveillance (Asghar et al., 2014; Fernández et al., 2012), with most recent strides in the surveillance of SARS-CoV-2 (Ahmed et al., 2020), but its application to AMR surveillance has only relatively recently gained significant traction (Fahrenfeld and Bisceglia, 2016). Recent wastewater AMR studies have investigated seasonal/geographic AMR distributions (Su et al., 2017), quantified global abundances of AMR genes (Hendriksen et al., 2019b) and identified associations between wastewater and clinical AMR surveillance data (Karkman et al., 2020; Pärnänen et al., 2019). However, heterogeneous study designs and methods likely contribute systematically to differences in outcomes/interpretations. The relative impact of study features such as grab sampling (i.e. taking single samples at a single timepoint) potentially collecting homogenous solids/unrepresentative samples (Reinthaler et al., 2013), interaction between snapshot/longitudinal sampling design and spatiotemporal variabilities, or sampling in the presence of unrepresentative, contaminating AMR-associated point sources are not well understood (Table 1). Difficulties in standardising AMR testing across traditional surveillance networks (Tacconelli et al., 2018) could be, for example, circumvented by using metagenomic sequencing to universally probe wastewater resistomes (Aarestrup and Woolhouse., 2020; Wright, 2007).

Despite increasing research in this area, there has been no attempt to review the available data, synthesise the evidence, and assess any remaining knowledge gaps. We therefore systematically reviewed studies using wastewater for AMR surveillance in human populations, seeking to identify practices that could optimise the association between wastewater-human AMR for surveillance purposes. We specifically focussed on study design 
87 to identify the relative potential impact of specific features on study outcomes, and to

88 highlight any limitations and recommendations for future research.

89

90 Results

91

Literature screen

92 Of 8,867 de-duplicated studies identified using our search strategy, full-text methods for 232 relevant studies were reviewed, and based on pre-specified inclusion criteria (see Methods), 29 studies were included in the review (Fig.1 and Fig.S1). Inter-rater reliability was assessed on a subset of 701 studies and gave a Cohen kappa score of 0.76 , indicating consistent screening across reviewers (Banerjee et al., 1999; Landis and Koch, 1977), and supporting screening of remaining study records by a single reviewer. Screening conflicts were observed for only $27 / 701$ (4\%) studies and were resolved by discussion.

Risk of bias

Three of twenty-nine studies were judged at high-risk of bias, 15 with an unclear-risk and 11 at low-risk (Supplementary datasets 1 and 2). Details and rationale behind this categorisation are in Supplementary dataset 1. 
wastewater and human AMR, but were not directly set up as wastewater-based AMR surveillance studies (e.g. studies focussed on one health and transmission). Amongst the twenty-nine included studies, 72 unique countries were sampled, although most (48/72) were represented as part of a single global study (Hendriksen et al., 2019b) (Fig.2). World Bank regions covered by the studies were as follows: East Asia and Pacific ( $n=3$ studies), Europe and Central Asia ( $n=16)$, Latin America and the Caribbean $(n=4)$, Middle East and North Africa $(n=8)$, North America $(n=5)$, South Asia $(n=2)$, Sub-Saharan Africa $(n=4)$. World Bank income classifications showed a sampling skew towards high-income countries (high income $[n=21$ studies]; middle income [n=10] and low income [n=3]) (Fig.S2). Three studies covered multiple regions and income classifications. Publication dates ranged from 2007-2020, with most published in the last three years $(n=20)$. Sampling years ranged from 2004-2019, with the most common being 2011-2016 ( $n=17$ ), and only three studies (Haghi et al., 2019; Pot et al., 2020; Urase et al., 2020) sampling in the last three years (for full study descriptions, see

\section{Supplementary datasets 2 and 3 ).}

\section{AMR evaluations in included studies}

Evaluations of AMR were undertaken using genotypic-only methods $(n=6)$, phenotypic-only methods $(n=8)$, or a mixed approach combining both $(n=15)$. Genotypic-only studies employed metagenomics $(n=4)$ and qPCR $(n=2)$. Phenotypic-only studies employed diskdiffusion $(n=3)$, microbroth dilution $(n=3)$, or both $(n=2)$. Mixed approach studies combined disk-diffusion/microbroth dilution with qPCR $(n=1), P C R(n=6)$ or single isolate whole genome sequencing (WGS) ( $n=8)$. For data synthesis and analysis across studies, relevant phenotypic data was extracted from 19 studies and genotypic data from nine studies (20 studies in total). 
131 For nine studies there were no relevant data that could be extracted for inclusion in a 132 combined summary; these were either where sample counts were not reported or only raw sequencing data was available which was beyond the scope of our analysis.

Phenotypic data from 19 studies covered twelve WHO Critically Important Antimicrobials (CIAs) for which overall resistance prevalence in wastewater and human isolates was reasonably high (CCC $=0.81[95 \% \mathrm{Cl} 0.74-0.87]$ ) (Fig.3A). The median number of comparisons (i.e. AMR prevalence for a specific species-drug across both wastewater and human compartments) per study was 4 (IQR: 2-7). For any comparison, the median number of isolates analysed in humans was 130 (IQR: 50-470), and in wastewater 98 (IQR: 58-356). AMR prevalences were in high agreement (defined as wastewater AMR prevalence within $\pm 10 \%$ of human AMR prevalence) for 59/99 (60\%) comparisons (Supplementary dataset 4). Hutinel et al., 2019 contributed the most comparisons in high agreement (13/16 comparisons withinstudy) while remaining studies contributed 1/1-6/7 each. Contribution of comparisons not in high agreement was similar across studies (1-4 each).

The most common species and antibiotic class investigated was $E$. coli and aminoglycosides respectively. When considering discordance across the top two represented species, 29/59 (49\%) comparisons of AMR prevalence in wastewater and human populations for $E$. coli showed $<5 \%$ discordance and $37 / 59(63 \%)$ of comparisons $\leq 10 \%$ discordance, whereas $6 / 17$ 
$<5 \%$ discordance and $8 / 17(47 \%) \leq 10 \%$ discordance (Fig.3A top right panel). Regarding differences between antibiotic classes, comparisons investigating cephalosporin resistance showed $\leq 10 \%$ discordance for $14 / 20(70 \%)$ of comparisons, while for beta-lactam resistance this was only true for 3/10 (30\%) (Fig.3A bottom right panel).

By individual antibiotics of interest, AMR prevalence estimates (i.e. point estimate $\pm 95 \%$ confidence intervals) in human and wastewater isolates overlapped for: (i) aminoglycosides (21/26 comparisons; Fig.S3); (ii) amoxicillin/ampicillin (6/10 comparisons; Fig.S4); (iii) betalactam/beta-lactamase inhibitor combinations (6/11 comparisons; Fig.S5); (iv) cephalosporins (13/20 comparisons; Fig.S6); (v) ertapenem (1/1 comparison; Fig.S7); (vi) fluoroquinolones/quinolones (6/16 comparisons; Fig.S8); (vii) vancomycin (2/3 comparisons; Fig.S9); and (viii) erythromycin (4/5 comparisons; Fig.S10). Overlap was also seen specifically for extended-spectrum beta-lactamase (ESBL)-producing isolates ( $2 / 3$ comparisons) and methicillin-resistant Staphylococcus aureus (MRSA) (1/1 comparison; both Fig.S11). Nonoverlapping estimates were mostly associated with five studies (Zarfel et al., 2010; Huijbers et al., 2020; Reinthaler et al., 2013; Saifi et al., 2009; Zaheer et al., 2020).

\section{Genotypic wastewater-human AMR comparisons}

For extracted genotypic data (single isolate WGS and PCR), prevalence of AMR genes in wastewater isolates was highly correlated with prevalence in human isolates (CCC $=0.88$ (95\% Cl 0.85-0.91)) (Fig.3B), with high agreement (wastewater AMR prevalence within $\pm 10 \%$ of human AMR prevalence) in 169/228 (74\%) comparisons. The median number of comparisons 
175 (i.e. AMR prevalence for a specific species-AMR gene combination across both wastewater 176 and human compartments) per study was 12 (IQR: 8-44). For any comparison, the median number of isolates analysed in humans was 94 (IQR: 25-437), and in wastewater 91 (IQR: 30388). Most high agreement comparisons were observed in Raven et al., 2019 (71/169), 179 followed by Adator et al., 2020b (33/169) and Zaheer et al., 2020 (19/169). Studies contributing the most comparisons not in high agreement were Pot et al., 2020 (17/59) and Adator et al., 2020b (12/59), while remaining studies contributed 1-8 each.

The most common species and AMR gene family investigated was E. coli and CTX-M respectively. When considering discordance across species, 95/145 (66\%) comparisons of AMR prevalence in wastewater and human populations for $E$. coli showed $<5 \%$ discordance and $120 / 145$ (83\%) of comparisons $\leq 10 \%$ discordance, while comparisons in Enterococcus spp. showed $17 / 44(39 \%)<5 \%$ discordance and 33/44 (74\%) $\leq 10 \%$ discordance. Enterobacter cloacae and Campylobacter spp. comparisons shared more even distributions of discordance levels (Fig.3B top right panel). For AMR gene family, comparisons of most gene families across compartments were in high agreement (i.e. $\leq 10 \%$ discordance) such as for CTX-M 20/28 (71\%), dfr 18/20 (90\%) and aad 14/16 (88\%) (Fig.3B bottom right panel).

For a subset of the eight most common genes conferring resistance to $\mathrm{WHO} \mathrm{ClA}$ antibiotics represented across studies, $95 \% \mathrm{Cl}$ around prevalence estimates in both compartments overlapped as follows: (i) aac (12/15 comparisons; Fig.S12 [displayed for individual allelic variants]); (ii) $\operatorname{arr}$ (1/2 comparisons; Fig.S13); (iii) CTX-M 22/26 comparisons; Fig.S14); (iv) erm 
197 (4/6 comparisons; Fig.S15); (v) fos (2/2 comparisons; Fig.S16); (vi) oxa (8/8 comparisons; Fig.S17); (vii) van (3/3 comparisons; Fig.S18) and (viii) qnr (3/4 comparisons; Fig.S19).

Study features potentially associated with higher wastewater-human AMR agreement.

201

If more than $70 \%$ of wastewater-human AMR prevalence comparisons conducted were in high agreement, studies were classed as high agreement overall; this was the case for $6 / 19$ studies (32\%) with phenotypic data and 4/9 (44\%) studies with genotypic data. Eight studies had both phenotypic and genotypic data available but only $1 / 8(13 \%)$ showed overall high agreement for both approaches (Adator et al., 2020b); remaining 7/8 either showed high agreement for only one approach or no high agreement at all. Total comparisons across approaches were used to classify studies for logistic regression. The strongest association was with the type of human sample analysed ( $p=0.23$, Table S20); the limited number of eligible studies, and the substantial heterogeneity of combinations of approaches deployed across studies, meant power to detect independent associations was low.

We therefore synthesised study features descriptively, also assigning studies to moderate $(30-70 \%)$ and low agreement categories (<30\%); keeping phenotypic- and genotypicapproaches separate. Sampling of influent, either alone or in conjunction with effluent, appeared most consistently associated with moderate-/high-agreement in estimates of AMR prevalence between wastewater and human compartments (Fig.4-Table S22). Most studies with extractable data conducted longitudinal sampling (24/28; 1 conducted both); this approach occurred in all three agreement categories (Fig.4A). The three studies undertaking 
219

220

221

snapshot (i.e. single-timepoint) sampling all had high-agreement $(n=2)$ and moderateagreement $(n=1)$. For longitudinal studies, the timeframe of sampling was potentially relevant: Of the seven low-agreement longitudinal studies, 6/7 sampled for $\leq 12$ months and only $1 / 7$ for $>12$ months. Conversely, $14 / 17$ medium/high-agreement longitudinal studies sampled for $>12$ months, and only $3 / 17$ for $<6$ months. (Fig.4B). Moderate-/high-agreement studies deployed several wastewater sampling methods, with composite, grab and flowproportional sampling showing no clear relationship with agreement (Fig.4C). Of note, sampling point or method was not reported by six studies. Most studies performed comparisons on wastewater at least in part derived from the human population sampled (i.e. direct comparisons, 19/28), while five conducted indirect comparisons, one conducted both and four were unclear/unreported. Most moderate-/high-agreement studies conducted direct comparisons (Fig.4D). Other study features showed even more variation across agreement categories but a smaller number of WwTWs sampled was potentially more associated to moderate-/high-agreement studies (Fig.S21 - Table S22).

\section{Studies without extractable data}

The nine studies without extractable data that could be synthesised are summarised below in terms of their overall ability to detect wastewater-human AMR associations based on reported conclusions. Full descriptive summaries including study details and specific findings are in supplementary dataset 5. 
241 Two studies performed direct AMR gene detection using qPCR of either 229 (Pärnänen et al., 242 2019) or eight AMR genes (Colomer-Lluch et al., 2014); both reported a relationship between wastewater AMR and national AMR data.

Four studies employed metagenomics to identify potential wastewater-human AMR associations. Two of these studies appeared to demonstrate an association while the other two were inconclusive.

Mixed-approach and phenotypic-only studies

251 Two studies used mixed approaches combining phenotypic AST with qPCR (2-targets) (Meirphenotypic approach only (YoungKeun et al., 2015). All three studies appeared to show a wastewater-human AMR association.

\section{Discussion}

From our review and synthesis of the available data, we found characterisation of AMR in wastewater shows promise in reflecting AMR in human populations, irrespective of diverse target species, target resistances and study locations, although associations may be stronger for some species and AMR mechanisms than others. The strength of this relationship varied across studies and was likely influenced by study design, setting, spatiotemporal sampling 
262

263

264

265

266

267

268

269

270

271

272

strategies, and testing approach (i.e. sample preparation, DNA extraction, target species/resistances and genotypic/phenotypic); the heterogeneity of methodological approaches and lack of clear reporting of key study features made any quantitative synthesis very difficult.

Our estimates of concordance (Fig.3A, 3B) supporting a wastewater-human AMR correlation are in line with estimates in individual studies (Huijbers et al., 2020; Hutinel et al., 2019;

Karkman et al., 2020). In particular, Huijbers et al., 2020 reported coefficients of determination as $0.62-0.72$ for individual antibiotics and 0.85 when data was combined for four antibiotic classes - similar to our findings of 0.81 and 0.88 for class-unrestricted phenotypic and genotypic data respectively. Although data was too limited to robustly estimate Lin's CCC for individual species and AMR, variability in the level of discordance of wastewater-human comparisons (Fig.3A, 3B - right panels) and overlap in 95\% $\mathrm{Cl}$ around point estimates (Fig.S3-19) is likely attributed in part to specific species and AMR that work best for wastewater-based AMR surveillance, which may vary with setting or over time, and those where the approach consistently works less well for. This phenomenon was also reported in several studies without extractable prevalence data where specific AMR classes/genes exhibited notably higher/lower wastewater-human agreement. The performance increase (non-significant) of genotypic comparisons seen in both Lin's CCC and in the reduced proportion of strongly discordant comparisons (Fig.3B right panels) may reflect the relatively species- and mechanism-agnostic nature of genotypic AMR detection methods (mostly WGS in extracted data) over phenotypic methods which may be more susceptible to variations from differing growth media/conditions and interpretation of 
resistance breakpoints. Problems with accurately characterising AMR prevalence when only small numbers of isolates are analysed (median of 94-130 for human and 91-98 for wastewater compartments across pheno-/genotypic comparisons here) is also a concern highlighted by previous researchers, particularly when few resistant isolates are available (Huijbers et al., 2020).

Although not a focus in our review, genotypic profiling potentially affords some additional advantages over phenotypic analyses, and is relevant to confirming that genetic mechanisms underpinning phenotypes are also similar. Genomic approaches, such as sequencing of isolates or whole sample metagenomics, enable a more agnostic approach to be adopted than for qPCR, in that analyses do not need to be restricted to a subset of predefined genes/gene variants. Genomic data and profiles can also be more readily shared with the wider community to allow for cross-study comparisons and data synthesis; as demonstrated by Karkman et al. Genomics approaches also allow for the evaluation of genetic relatedness and quantitation of either isolates or microbial populations across compartments (e.g. through phylogenetics, taxonomic/strain-level profiling and strainbased comparisons using metagenomes). Genomic approaches may be higher-resolution and more flexible, but at a higher resource cost; sensitivity for the detection of AMR genes is also dependent on sequencing depth, and accurately associating specific AMR gene markers with strains or species in short-read based metagenomes remains difficult (Gweon et al., 2019). 
307
Our review highlights the need for clear guidance on performing these studies in a more standardised way, with a view to consolidating best-practice approaches in a workflow whilst enabling some flexibility to account for differences in any given setting. WwTW influent is likely the most population-representative wastewater sample for AMR surveillance using either phenotypic or genotypic approaches. This is not unexpected, as previous studies have described transformation of microbial and AMR gene composition during treatment (Tong et al., 2019; Zhang et al., 2020). Transformed samples may remain useful for wastewater-based AMR surveillance, potentially dependent on treatment process; however differing levels of treatment have been shown to select for different species/AMR determinants (Tong et al., 2019). Additionally, a temporospatial overlap of wastewater sampled and the target surveillance population is likely helpful; a feature of the majority of moderate-/high-agreement studies as well as sampling fewer WwTWs which may also relate to the closeness of the populations compared.

Composite sampling also seems sensible as wastewater composition changes significantly over short timescales (Guo et al., 2019) and individual grab samples may be "flooded" by homogenous solid material (Reinthaler et al., 2013). However, grab sampling is convenient and avoids significant autosampler-associated workload and capital costs, and was the most common sampling method used in the studies analysed. Further research is needed into characterising how effectively single timepoint grab samples versus composite/proportional samples reflect temporal AMR changes. 
Longitudinal sampling with timeframes over 12 months was most common in both phenotypic and genotypic high agreement studies, consistent with data from two studies which could not be directly synthesised (Hendriksen et al., 2019a; Pignato et al., 2010). In these studies, both used two-weekly sampling intervals over 12- and 3-month timeframes respectively. The former observed an association between ampicillin-resistant wastewater and contemporaneous clinical isolates, whereas the latter found no relationship between contemporaneous public health surveillance and wastewater metagenomic read abundances.

Future studies should clearly report sewer inputs, including any unique AMR-associated inputs (e.g. hospitals, agricultural sources) that may obscure the detection of a wastewaterhuman AMR association (Fahrenfeld and Bisceglia, 2016). The importance of specific AMRassociated inputs is likely linked to whether the AMR mechanisms under evaluation are associated with that specific source, or already widely disseminated in the community. For example, one study (Raven et al., 2019) sampled WwTWs with and without hospital input, and found the most clinically-prevalent E. coli ESBL gene was ubiquitous in all WwTWs, indicating prior widespread dissemination. Another study (Jakobsen et al., 2008) focussing on E. coli gentamicin resistance in hospital effluent, receiving WWTW influent and domesticonly wastewater, found significantly lower prevalence in domestic-only wastewater compared to hospital effluent and WwTW influent which shared similar prevalence, indicating that the presence of any hospital-associated wastewater in influent would confound any community-based estimates. Additional metadata such as sample storage 
351

352

353

354

355

356

357

358

359

360

361

362

363

364

365

366

367

conditions or freeze/thaw cycles are also pertinent to interpretation as investigated by

Poulsen et al., who similarly suggested detailed reporting of these features.

Our study has several limitations. We were not resourced to conduct duplicate screening by two reviewers; however, the risk of single reviewer bias was mitigated by validating the screening strategy using three reviewers on a subset of records. We excluded non-English publications, potentially missing some relevant studies. Studies were highly diverse in reported features, design and outcomes, making a comprehensive synthesis difficult. In particular, many features were poorly characterised and could not be explored in our analyses. For our study feature analysis we focused a priori on features that optimised the identification of an association between wastewater and human AMR prevalence, however it may be that in some circumstances there is genuinely no such association. In many settings globally, established wastewater infrastructures are not available, and an analysis of, for example, WwTW influent may not be feasible.

\section{Conclusion}

In conclusion our review suggests that overall, wastewater-based surveillance of populationlevel AMR appears relatively robust, despite high diversity in study design, methods and metadata. However, based on limited available data, we would recommend that where feasible, composite sampling of influent with longitudinal timeframe $>12$ months, and contemporaneous sampling of wastewater and human samples that are directly associated (i.e. the human population sampled contributes to the wastewater sampled) are used to 
373

374

generate more robust data to better evaluate the strengths and limitations of this approach for surveillance purposes. Clear reporting of study methods and features are essential, and this will facilitate the development of optimal practice guidelines for this emerging surveillance tool.

\section{Materials and Methods}

For this systematic review, we adopted the "Population Intervention Comparator Outcome" (PICO) framework using the following domains: Wastewater, antimicrobial resistance, bacteria and public health surveillance/methods. A PRISMA checklist is included in (Supplementary dataset 6), and the complete PROSPERO protocol is available at:

\section{https://www.crd.york.ac.uk/prospero/display record.php?ID=CRD42019134946.}

\section{Literature search}

The search string was developed through iterative preliminary searches in consultation with a librarian experienced with systematic reviews. Full search strings adapted for each database are presented in (Supplementary dataset 7). Searches were conducted on 01/02/2019 in: MEDLINE, EMBASE, Global Health, CAB Abstracts, Scopus and Web of Science Core Collection. Searches were updated on 09/01/2021 using identical search strings. Results were limited to the English language and de-duplicated.

\section{Eligibility criteria}


Study titles/abstracts were screened with a series of questions (see Fig.S1) to determine if the study was: (i) primary research, (ii) collected human-associated wastewater, (iii) reported AMR prevalence, and (iv) performed a comparison between the wastewater dataset and another human-associated dataset. Studies explicitly performing wastewater-based surveillance of human AMR were included using parallel criteria. If it was unclear whether a study met criteria based on title and abstract alone, the study was passed onto the next stage. For studies that passed the initial screen, full-text methods were reviewed and studies included if they: (i) analysed wastewater samples/data from a wastewater treatment facility, and (ii) represented a human population through their non-wastewater dataset; or (iii) conducted a self-defined wastewater-based AMR surveillance study as the study aim.

\section{Study selection and data extraction}

Three reviewers (KKC, LB, NSi) independently screened a random subset of $8 \%$ of total retrieved study records to estimate Cohen's Kappa score (Cohen, 1960) as a measure of interreviewer reliability beyond chance. As this score supported sufficiently consistent screening across reviewers, the remaining records were screened by a single reviewer (KKC).

For included records, data were extracted by two reviewers (KKC, LB) using a pre-tested data extraction form piloted on five random included records (Supplementary dataset 8), including (non-exhaustive): study design (wastewater sampling strategy/site/methods, AMR detection methods, human sample type, sample sizes) and outcomes (AMR prevalence, wastewater-human comparison results). Raw resistance prevalence data (total and resistant 
416

isolate counts) were extracted if available. Phenotypic data extraction was limited to antibiotics on the WHO critically important antimicrobials (CIAs) list (AGISAR, 2018) to maintain clinical relevance. Genotypic data was extracted in full; individual gene analysis was however only undertaken for a subset of AMR genes that conferred resistance to CIAs and were characterised in multiple studies. Any statistical methods or modelling approaches were also recorded.

\section{Risk of bias assessment}

Risk of bias was assessed independently by two reviewers (KKC, LB) using a qualitative approach based on the Cochrane risk of bias tool (Higgins et al., 2011) addressing five bias domains (Supplementary dataset 1); the modified tool focused on systematic differences at the study level as outcomes reported were highly diverse. Studies at "high-risk" of bias were those with inconsistencies in sampling, AMR detection methods, measurement and reporting of outcomes; "low-risk" studies broadly maintained consistency across comparators. If information present was insufficient to assess risk of bias the classification "unclear" was assigned. Discrepancies were resolved by discussion until consensus was met, and an overall qualitative measure (high, low and unclear) was assigned to each study; primarily based on the majority of domain judgements (details in Supplementary dataset 1).

\section{Data synthesis and analysis}

For extracted resistance prevalence data, we used Lin's concordance correlation coefficient (CCC - R package DescTools) with $95 \%$ confidence intervals (Cls) to quantify the agreement 
between the proportion of resistant wastewater isolates and the proportion of resistant human isolates, with the latter representing the reference standard. As perfect concordance is unrealistic, we arbitrarily defined high agreement to be a $\pm 10 \%$ difference in resistance prevalence between wastewater and human compartments. Since Lin's CCC does not reflect error in resistance proportion estimates, we also plotted and compared resistance prevalence and Clopper-Pearson $95 \%$ Cls by study and antibiotic or AMR gene.

As we aimed to identify study approaches that could maximise the association between wastewater-human AMR for surveillance purposes, we investigated study features associated with "high agreement", defined as $>70 \%$ of the comparisons of speciesphenotype or species-genotype AMR prevalence estimates in wastewater and human compartments within-study being within $\pm 10 \%$ of each other. As study feature reporting was highly inconsistent, we only considered features that were broadly reported across studies. We then used logistic regression to identify if any study features were associated with this high agreement classification in STATA/IC v.16.1 (StataCorp, College Station, USA).

In addition, given the heterogeneity of study features, their inconsistent reporting across studies, and the small number of studies limiting power to detect associations, we also descriptively synthesised features potentially associated with wastewater-human AMR agreement, using a modified version of the harvest plot, specifically designed to help assimilate findings where a quantitative synthesis is not feasible (Ogilvie et al., 2008). For this, in addition to the high agreement category specified above, we also assigned studies to 
460 moderate (30-70\%) and low agreement categories (<30\%); keeping phenotypic- and 461 genotypic-approaches separate. 
Table 1: Potential sources of variation in wastewater-based AMR surveillance studies

\begin{tabular}{|c|c|c|c|}
\hline $\begin{array}{l}\text { Aspects for } \\
\text { consideration }\end{array}$ & Examples & Key variabilities & References \\
\hline $\begin{array}{l}\text { Wastewater } \\
\text { sampling point }\end{array}$ & $\begin{array}{l}\text { - WwTW influent/during } \\
\text { treatment/effluent } \\
\text { - Hospital effluent } \\
\text { - Domestic } \\
\text { sewers/manholes } \\
\text { - Informal sewer } \\
\text { systems (LMICs) }\end{array}$ & $\begin{array}{l}\text { - Treatment processes can transform } \\
\text { microbial and AMR composition } \\
\text { - Focussed sampling may only represent } \\
\text { specific sub-populations* } \\
\text { - Informal sewer systems (often with low } \\
\text { flow) may be susceptible to homogeneity }\end{array}$ & $\begin{array}{l}\text { (Fahrenfeld and } \\
\text { Bisceglia, 2016; } \\
\text { Jakobsen et al., } \\
\text { 2008; Larson et } \\
\text { al., 2020; Tong et } \\
\text { al., 2019; Zhang } \\
\text { et al., 2020) }\end{array}$ \\
\hline $\begin{array}{l}\text { Wastewater } \\
\text { sampling } \\
\text { method }\end{array}$ & $\begin{array}{l}\text { - Grab (single sample) } \\
\text { - Composites } \\
\text { - Proportional sampling } \\
\text { (flow/time/volume) }\end{array}$ & $\begin{array}{l}\text { - Single grab samples can be flooded by } \\
\text { homogenous solids } \\
\text { - Wastewater composition can vary } \\
\text { significantly over short time periods } \\
\text { - Composite and proportional samples will } \\
\text { capture average composition but may be } \\
\text { unable to discriminate peak values during } \\
\text { sampling period* }\end{array}$ & $\begin{array}{l}\text { (Guo et al., 2019; } \\
\text { Michael-kordatou } \\
\text { et al., 2020; } \\
\text { Reinthaler et al., } \\
\text { 2013) }\end{array}$ \\
\hline $\begin{array}{l}\text { WwTW } \\
\text { sewershed } \\
\text { inputs }\end{array}$ & $\begin{array}{l}\text { - Hospitals } \\
\text { - Other healthcare } \\
\text { facilities (e.g. } \\
\text { carehomes) } \\
\text { - Agriculture } \\
\text { - Industry }\end{array}$ & $\begin{array}{l}\text { - Effluent from AMR-associated sources may } \\
\text { obscure detection of true population-level } \\
\text { trends (e.g. elevated levels of unique AMR, } \\
\text { co-selection of plasmids, non-human } \\
\text { associated AMR)* }\end{array}$ & $\begin{array}{l}\text { (Fahrenfeld and } \\
\text { Bisceglia, 2016; } \\
\text { Jakobsen et al., } \\
\text { 2008; Larson et } \\
\text { al., 2020) }\end{array}$ \\
\hline $\begin{array}{l}\text { WwTW } \\
\text { properties and } \\
\text { sampling } \\
\text { conditions }\end{array}$ & $\begin{array}{l}\text { - Size of WwTW } \\
\text { sewershed } \\
\text { - Treatment methods } \\
\text { - Infrastructure/design } \\
\text { - Weather (seasons, } \\
\text { rainfall, temperature) } \\
\text { - Flow rate }\end{array}$ & $\begin{array}{l}\text { - Long conveyance times from population to } \\
\text { sampling point may impact composition } \\
\text { due to transformation in unique } \\
\text { environment of the sewer system } \\
\text { (anaerobic, temperature, biofilms) } \\
\text { - When sampling treated wastewater, } \\
\text { differing levels of treatment can selectively } \\
\text { transform AMR and microbial composition } \\
\text { - Presence of pre-treatment infrastructure } \\
\text { (e.g. pumping stations, balancing tanks) } \\
\text { may also play a role in transforming } \\
\text { wastewater } \\
\text { - Heavy rainfall may dilute wastewater in } \\
\text { combined sewer systems via rainwater } \\
\text { runoff and by infiltration of groundwater } \\
\text { (dislodged biofilms, infiltration of } \\
\text { freshwater microorganisms) } \\
\text { - Combined sewer overflows will impact } \\
\text { composition of post-treatment samples } \\
\text { collected during events } \\
\text { - Flow rate is associated to hydraulic } \\
\text { retention time and the level of WwTW } \\
\text { treatment - impacting treated samples }\end{array}$ & $\begin{array}{l}\text { (Fahrenfeld and } \\
\text { Bisceglia; } \\
\text { Pehrsson et al., } \\
\text { 2016; Shanks et } \\
\text { al., 2013; Tong et } \\
\text { al., 2019) }\end{array}$ \\
\hline
\end{tabular}




\begin{tabular}{|c|c|c|c|}
\hline $\begin{array}{l}\text { Aspects for } \\
\text { consideration }\end{array}$ & Examples & Key variabilities & References \\
\hline $\begin{array}{l}\text { Wastewater } \\
\text { processing } \\
\text { methods }\end{array}$ & $\begin{array}{l}\text { - Filtration } \\
\text { - Storage conditions } \\
\text { - Addition of sodium } \\
\text { thiosulfate (chlorine } \\
\text { neutraliser) } \\
\text { - Freeze-thaw cycles } \\
\text { - DNA extraction } \\
\text { methods }\end{array}$ & $\begin{array}{l}\text { - Different wastewater processing methods } \\
\text { may selectively affect recovery yields of } \\
\text { specific species* } \\
\text { - Multiple freeze-thaw cycles shown to select } \\
\text { for Firmicutes, Actinobacteria, and } \\
\text { eukaryotic microorganisms } \\
\text { - Use of different metagenomic DNA } \\
\text { extraction kits and procedures has been } \\
\text { shown to modulate inferred microbial } \\
\text { composition* }\end{array}$ & $\begin{array}{l}\text { (Ahmed et al., } \\
\text { 2020; Knudsen et } \\
\text { al., 2016; } \\
\text { Michael-kordatou } \\
\text { et al., 2020; } \\
\text { Poulsen et al., } \\
\text { 2021) }\end{array}$ \\
\hline $\begin{array}{l}\text { AMR detection } \\
\text { method }\end{array}$ & $\begin{array}{l}\text { - Phenotypic culture- } \\
\text { based (selective } \\
\text { media, disk-diffusion, } \\
\text { microbroth dilution) } \\
\text { - Genotypic culture- } \\
\text { based (WGS, PCR, } \\
\text { qPCR) } \\
\text { - Direct-from-sample } \\
\text { genotypic (qPCR, } \\
\text { metagenomics) }\end{array}$ & $\begin{array}{l}\text { - Culture-based methods may be subject to } \\
\text { variations from phenotyping method and } \\
\text { breakpoint selection } \\
\text { - Methods based on culturing isolates may } \\
\text { only capture a fraction of the diversity } \\
\text { present even with detailed sampling } \\
\text { - Targeted genomic approaches are } \\
\text { restricted to a subset of predefined } \\
\text { genes/gene variants } \\
\text { - Bioinformatic deconvolution can be subject } \\
\text { to variation based on } \\
\text { tools/databases/references utilised - } \\
\text { especially for short-reads and plasmids }\end{array}$ & $\begin{array}{l}\text { (Davies, 2019; } \\
\text { Davies et al., } \\
\text { 2020; Lal Gupta } \\
\text { et al., 2020; } \\
\text { Shaw et al., 2021) }\end{array}$ \\
\hline
\end{tabular}


Figure 1: PRISMA flowchart of search strategy and study inclusions/exclusions
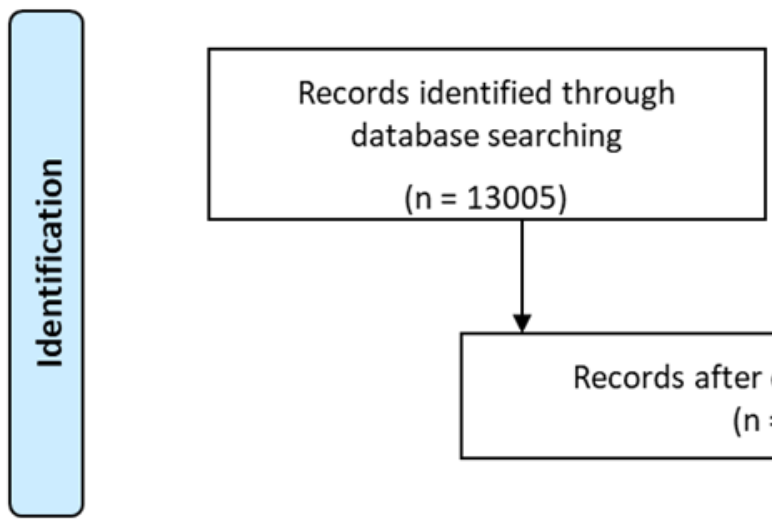

Records after duplicates removed

$(n=8867)$
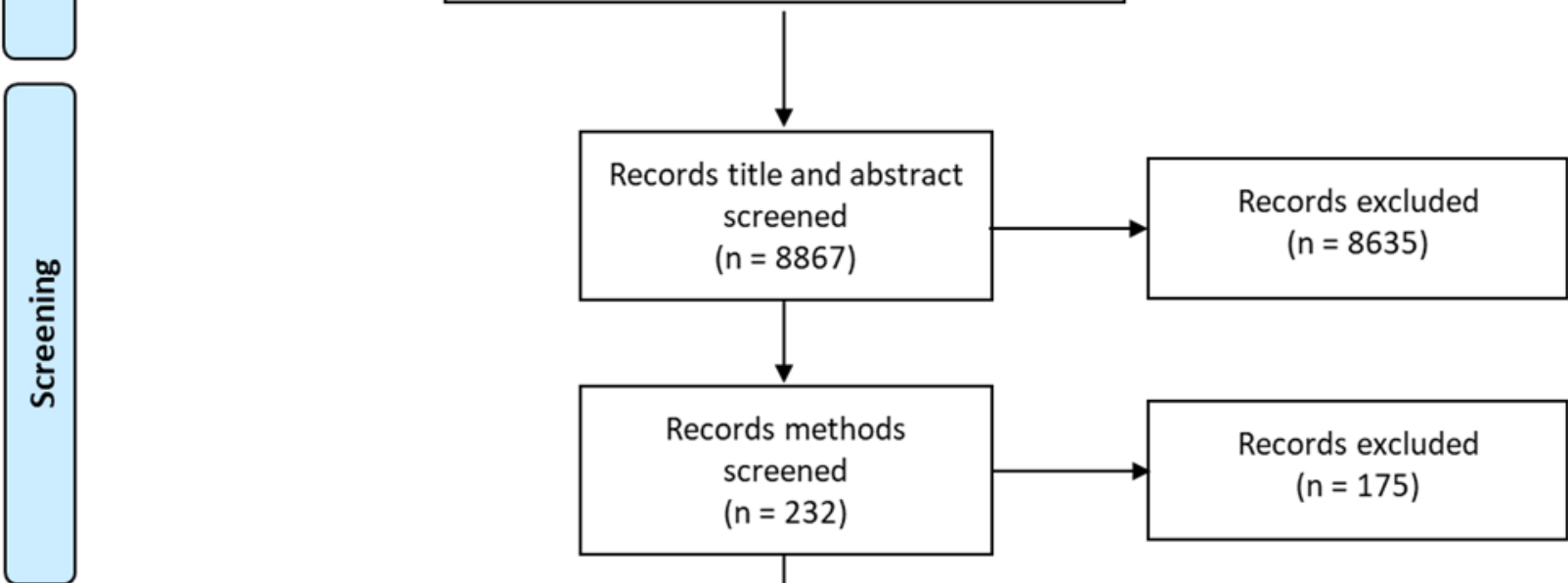

Records methods screened

$(n=232)$

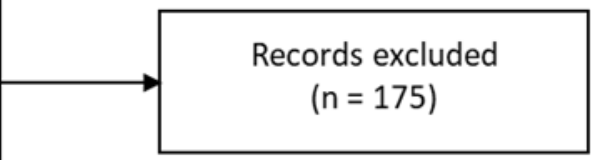

Full-text articles assessed for eligibility ( $n=57$ )

Full-text articles excluded, with reasons $(n=28)$

Studies included in qualitative synthesis $(n=29)$ 
474 Centroids of countries sampled by included studies are plotted with colours and shapes according to

475 citation and test approach respectively. Non-Hendriksen (GSSP-global sewage surveillance project)

476 studies are plotted with jitter around the centroid for the map focussing on Europe. AST=antimicrobial

477 susceptibility testing
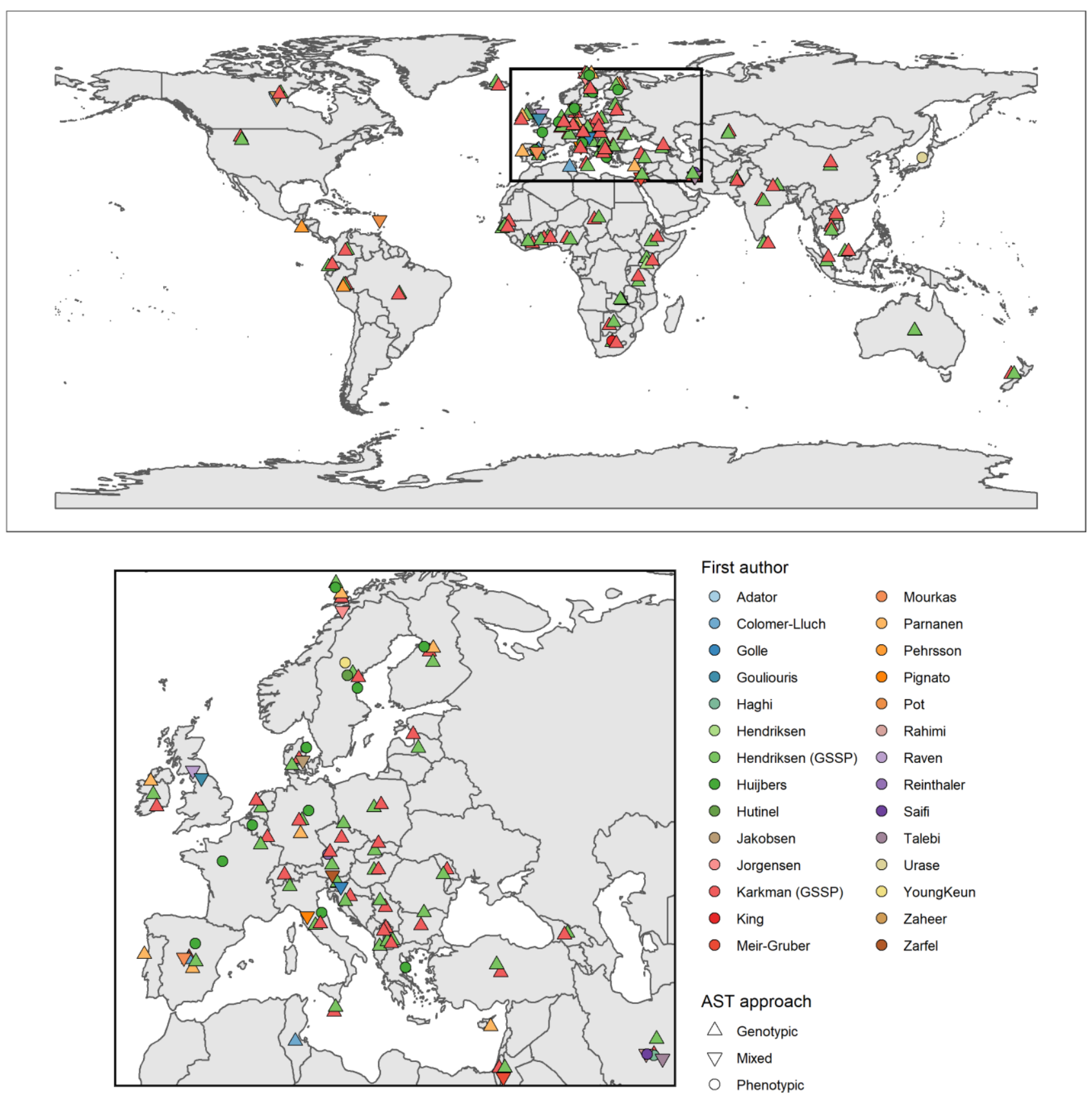

First author

$\begin{array}{llll}\bigcirc \text { Adator } & \bigcirc & \text { Mourkas } \\ \bigcirc & \text { Colomer-Lluch } & \bigcirc & \text { Parnanen } \\ \bigcirc & \text { Golle } & \bigcirc & \text { Pehrsson } \\ \bigcirc & \text { Gouliouris } & \bigcirc & \text { Pignato } \\ \bigcirc & \text { Haghi } & \bigcirc & \text { Pot } \\ \bigcirc & \text { Hendriksen } & \bigcirc & \text { Rahimi } \\ \bigcirc & \text { Hendriksen (GSSP) } & \bigcirc & \text { Raven } \\ \bigcirc & \text { Huijbers } & \bigcirc & \text { Reinthaler } \\ \bigcirc & \text { Hutinel } & \bigcirc & \text { Saifi } \\ \bigcirc & \text { Jakobsen } & \bigcirc & \text { Talebi } \\ \bigcirc & \text { Jorgensen } & \bigcirc & \text { Urase } \\ \bigcirc & \text { Karkman (GSSP) } & \bigcirc & \text { YoungKeun } \\ \bigcirc & \text { King } & \bigcirc & \text { Zaheer } \\ \bigcirc & \text { Meir-Gruber } & \bigcirc & \text { Zarfel }\end{array}$

AST approach

$\triangle$ Genotypic

$\nabla$ Mixed

O Phenotypic 
Figure 3: AMR in wastewater isolates and human isolates for phenotypic (A) and genotypic (B)

479

480

481

482

483

484

485

486

487 comparisons.

Left: Concordance plot of AMR prevalence in wastewater and human isolates stratified by AMR detection approach (i.e. phenotypic versus genotypic approaches). Each point represents a single wastewater-human comparison conducted and is coloured by bacterial species tested and human sample type used. Lin's concordance coefficient (CCC) is labelled with $95 \%$ confidence intervals.

Unbroken line of $y=x$ is plotted as perfect concordance between wastewater and human resistance.

Dashed lines of $y=x+0.1$ and $y=x-0.1$ represent high agreement, i.e. $\pm 10 \%$ from perfect concordance respectively. Right: Grouping of comparisons from concordance plot by level of discordance into categories for species and antibiotic class or AMR gene family.

\section{(A) Phenotypic comparisons}

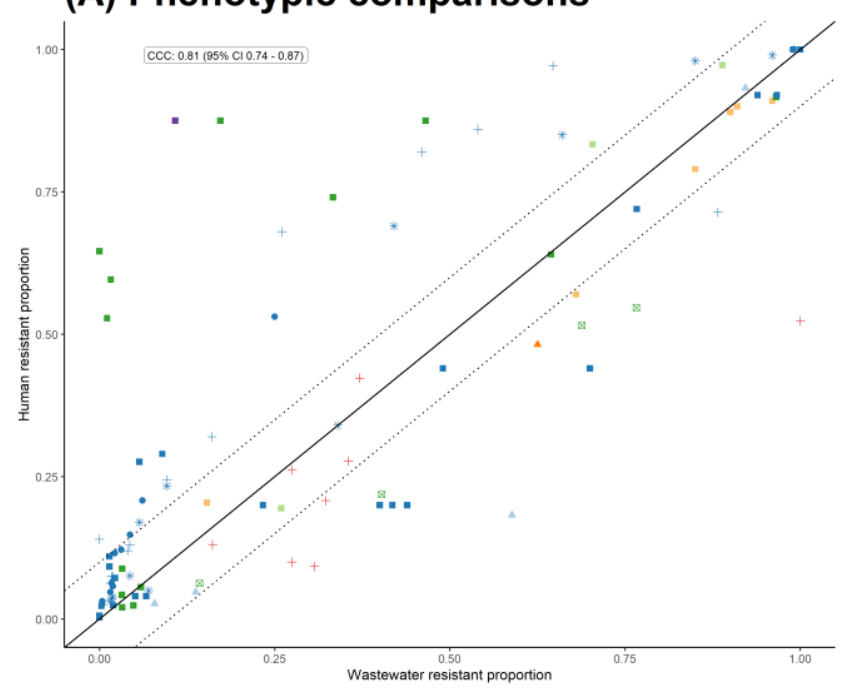

(B) Genotypic comparisons

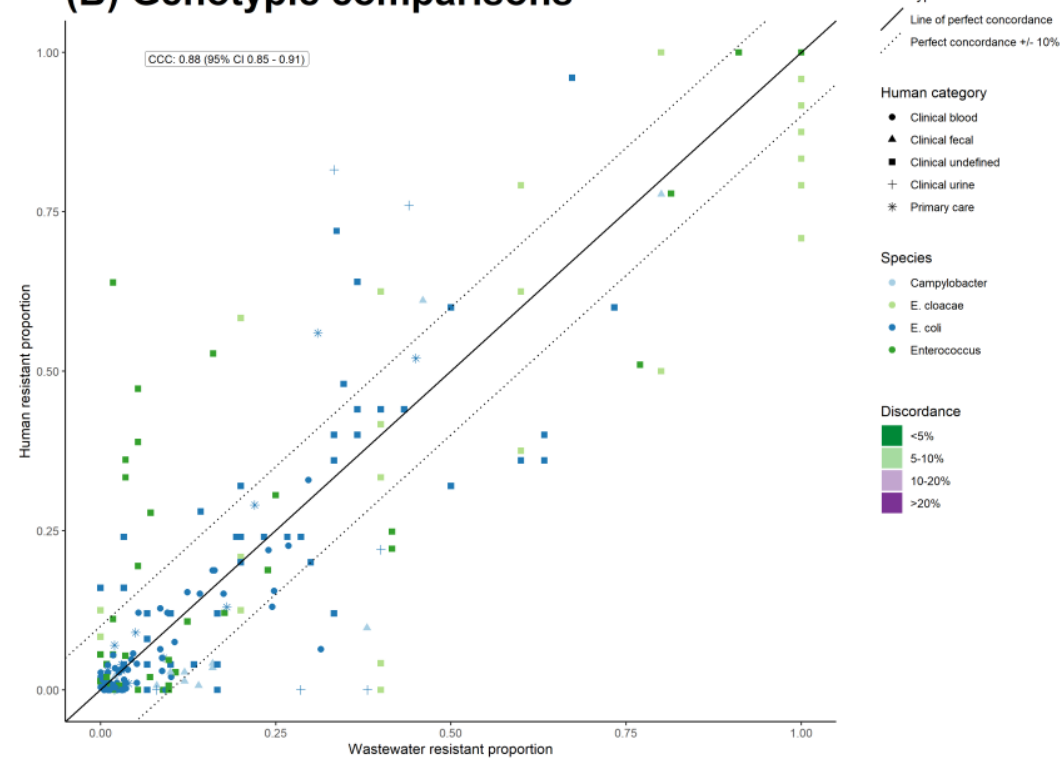

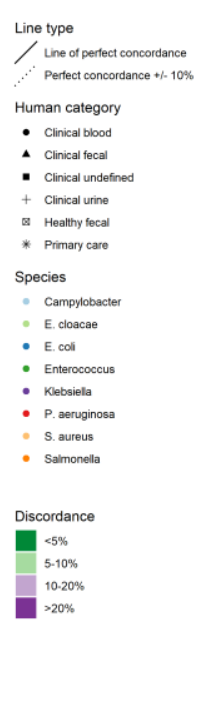
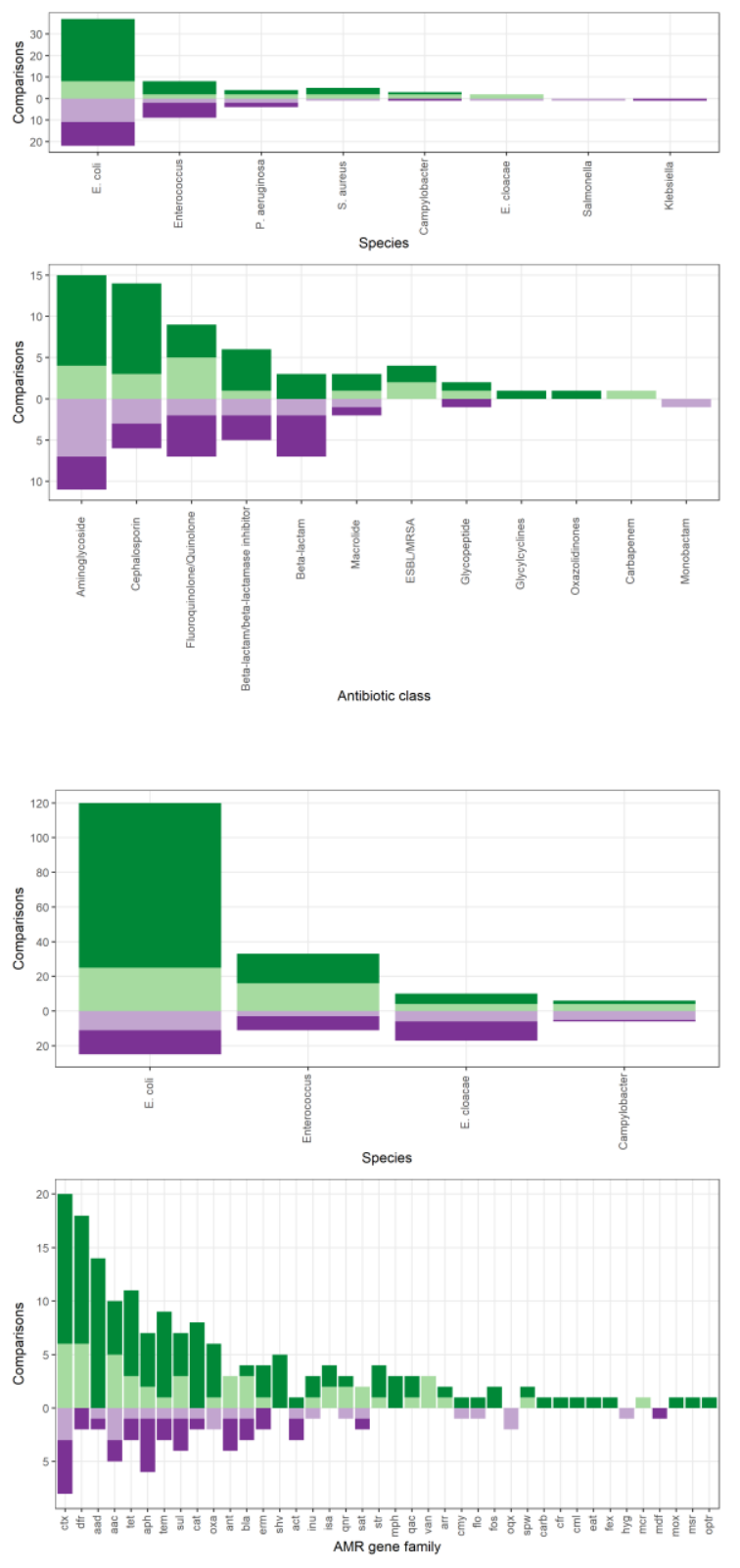
Figure 4: Study design features split by study-level agreement and wastewater sampling point.

489

Modified harvest plot of most widely reported study features $(A, B, C, D)$ in relation to wastewater

490 sampling point (horizontal facet) and overall study-level agreement (vertical facet). Study features are

491 coloured and bar height relates to number of studies with the feature.

A

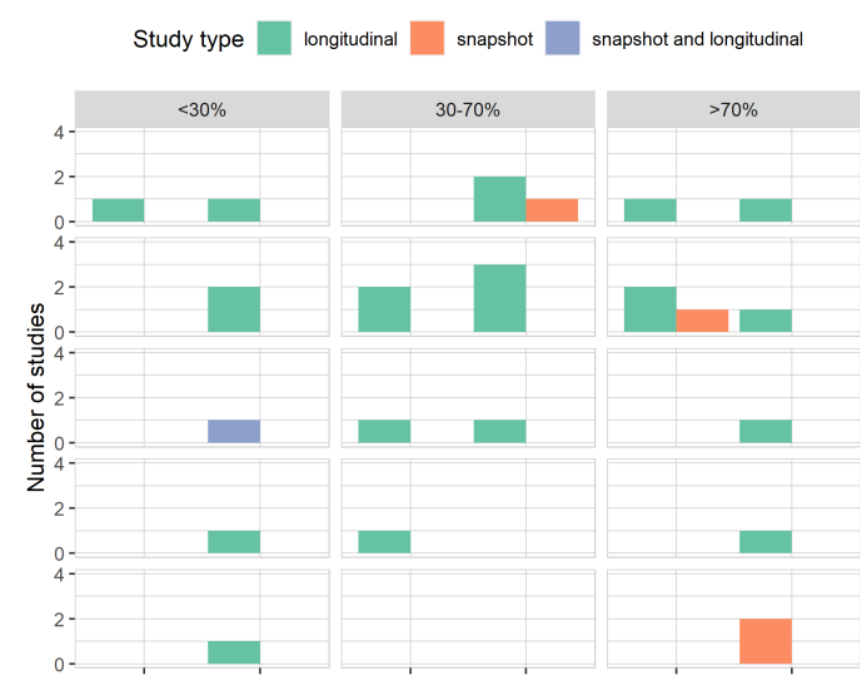

C
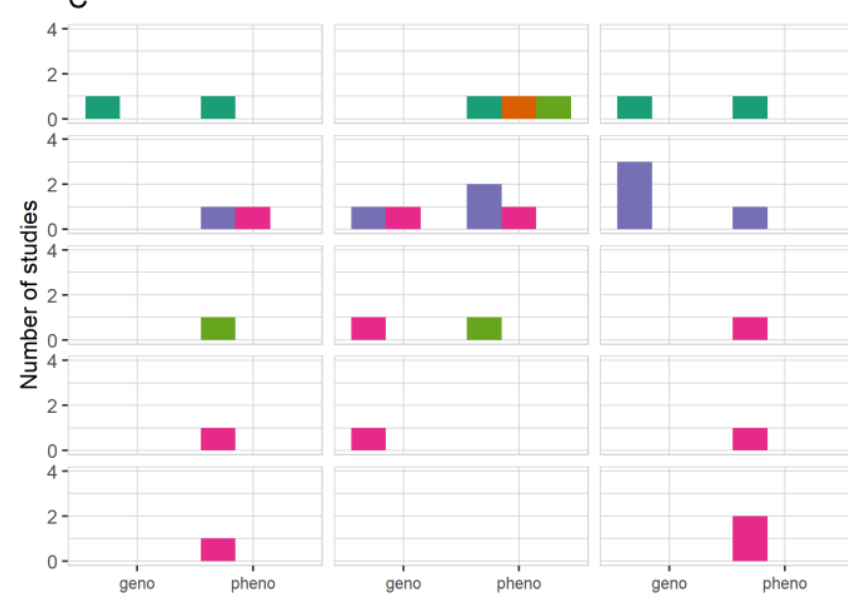

B

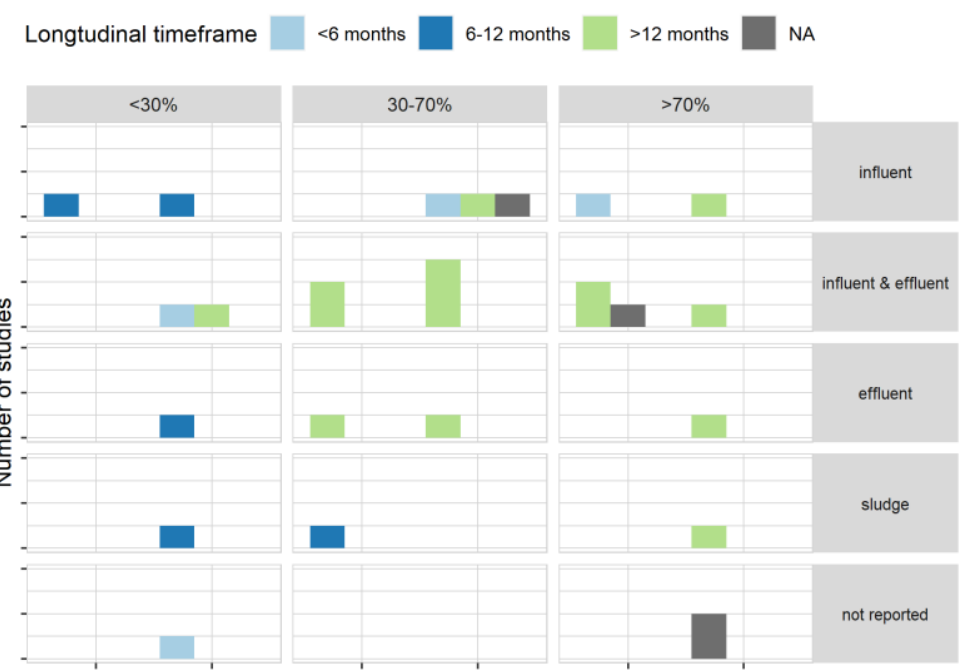

D

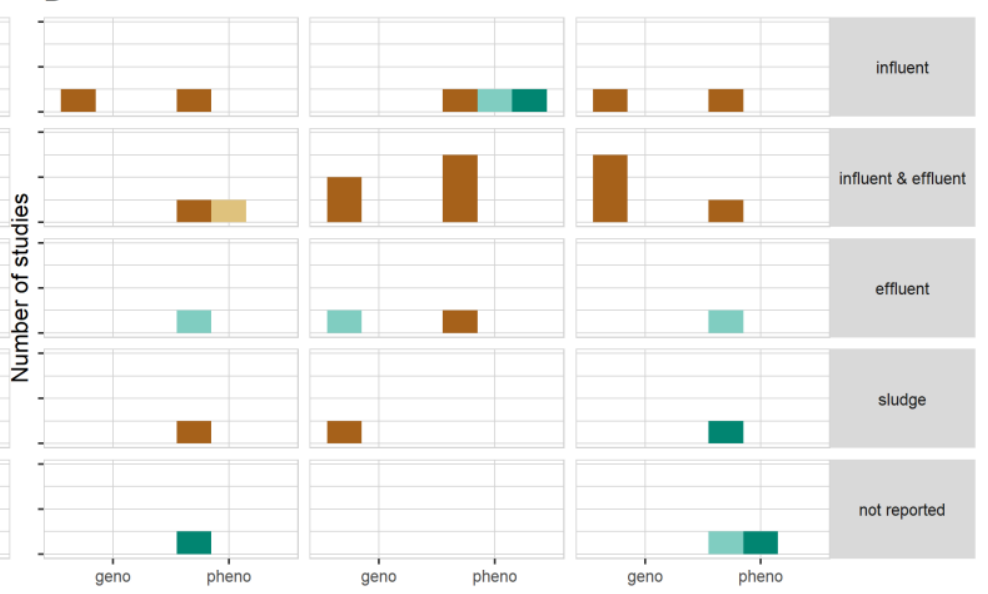

Sampling method

flow-proportional grab

Comparison type

Direct Direct \& Indirect

Indirect

Unclear

492 


\section{Contributors}

496 A complete list of author contributions is given in the appendix (p17).

\section{Competing interests}

498 The authors report no conflicts of interest.

\section{$499 \quad$ Funding}

500 This work was supported by the Medical Research Foundation National PhD Training Programme in

501 Antimicrobial Resistance Research, the National Institute for Health Research (NIHR) Health

502 Protection Research Unit in Healthcare Associated Infections and Antimicrobial Resistance at

503 University of Oxford (NIHR200915) in partnership with Public Health England (PHE), and the NIHR

504 Oxford Biomedical Research Centre. The report presents independent research. The views expressed

505 in this publication are those of the authors and not necessarily those of the NHS, NIHR, or the

506 Department of Health.

507

KKC is a Medical Research Foundation PhD student (ref. MRF-145-0004-TPG-AVISO). NS is an Oxford

508 Martin School fellow and an NIHR Oxford BRC Senior Research Fellow. ASW is an NIHR Senior

509 Investigator.

510 


\section{References}

517

518

519

520

521

522

523

524

525

526

527

528

529

530

531

532

533

534

535

536

537

538

539

540

541

542

543

544

545

546

547

548

549

550

551

552

Aarestrup F.M., Woolhouse M.E.J., 2020. Using sewage for surveillance of antimicrobial resistance. Science (80-.). 367, 630-632.

https://doi.org/http://dx.doi.org/10.1126/science.aba3432

Adator, E.H., Narvaez-Bravo, C., Zaheer, R., Cook, S.R., Tymensen, L., Hannon, S.J., Booker, C.W., Church, D., Read, R.R., McAllister, T.A., 2020a. A One Health Comparative Assessment of Antimicrobial Resistance in Generic and Extended-Spectrum Cephalosporin-Resistant Escherichia coli from Beef Production, Sewage and Clinical Settings. Microorganisms 8. https://doi.org/10.3390/microorganisms8060885

Adator, E.H., Walker, M., Narvaez-Bravo, C., Zaheer, R., Goji, N., Cook, S.R., Tymensen, L., Hannon, S.J., Church, D., Booker, C.W., Amoako, K., Nadon, C.A., Read, R., McAllister, T.A., 2020b. Whole Genome Sequencing Differentiates Presumptive Extended Spectrum BetaLactamase Producing Escherichia coli along Segments of the One Health Continuum. Microorganisms 8. https://doi.org/https://dx.doi.org/10.3390/microorganisms8030448

AGISAR, 2018. Critically Important Antimicrobials for Human Medicine 6th Revision 2018. Ranking of medically important antimicrobials for risk management of antimicrobial resistance due to non-human use., Https://Apps.Who.Int/Iris/Bitstream/Handle/10665/312266/9789241515528-Eng.Pdf?Ua=1.

Ahmed, W., Angel, N., Edson, J., Bibby, K., Bivins, A., O’Brien, J.W., Choi, P.M., Kitajima, M., Simpson, S.L., Li, J., Tscharke, B., Verhagen, R., Smith, W.J.M., Zaugg, J., Dierens, L., Hugenholtz, P., Thomas, K. V., Mueller, J.F., 2020. First confirmed detection of SARS-CoV-2 in untreated wastewater in Australia: A proof of concept for the wastewater surveillance of COVID-19 in the community. Sci. Total Environ. https://doi.org/10.1016/j.scitotenv.2020.138764

Ahmed, W., Bivins, A., Bertsch, P., Bibby, K., Choi, P., Farkas, K., Gyawali, P., Hamilton, K., Haramoto, E., Kitajima, M., Simpson, S., Tandukar, S., Thomas, K. and Mueller, J., 2020. Surveillance of SARS-CoV-2 RNA in wastewater: Methods optimization and quality control are crucial for generating reliable public health information. Current Opinion in Environmental Science \& Health, 17, 82-93. https://doi.org/10.1016/j.coesh.2020.09.003 Asghar, H., Diop, O.M., Weldegebriel, G., Malik, F., Shetty, S., Bassioni, L. El, Akande, A.O., Maamoun, E. Al, Zaidi, S., Adeniji, A.J., Burns, C.C., Deshpande, J., Oberste, M.S., Lowther, S.A., 2014. Environmental surveillance for polioviruses in the global polio eradication initiative. J. Infect. Dis. 210, S294-S303. https://doi.org/10.1093/infdis/jiu384

Banerjee, M., Capozzoli, M., McSweeney, L., Sinha, D., 1999. Beyond kappa: A review of interrater agreement measures. Can. J. Stat. https://doi.org/10.2307/3315487

Cohen, J., 1960. A Coefficient of Agreement for Nominal Scales. Educ. Psychol. Meas. https://doi.org/10.1177/001316446002000104 
553 Colomer-Lluch, M., Calero-Cáceres, W., Jebri, S., Hmaied, F., Muniesa, M., Jofre, J., 2014.

554 Antibiotic resistance genes in bacterial and bacteriophage fractions of Tunisian and Spanish 555 wastewaters as markers to compare the antibiotic resistance patterns in each population.

556 Environ. Int. 73, 167-175. https://doi.org/10.1016/j.envint.2014.07.003

557 Davies, Timothy J., 2019. Whole Genome Sequencing and Resistance in Escherichia Coli. PhD 558 thesis, University of Oxford.

559 Davies, T., Stoesser, N., Sheppard, A., Abuoun, M., Fowler, P., Swann, J., Quan, T., Griffiths, 560 D., Vaughan, A., Morgan, M., Phan, H., Jeffery, K., Andersson, M., Ellington, M., Ekelund, O., 561 Woodford, N., Mathers, A., Bonomo, R., Crook, D., Peto, T., Anjum, M. and Walker, A., 2020. 562 Reconciling the Potentially Irreconcilable? Genotypic and Phenotypic Amoxicillin-

563 Clavulanate Resistance in Escherichia coli. Antimicrobial Agents and Chemotherapy, 64(6). 564 https://doi.org/10.1128/AAC.02026-19

Fahrenfeld, N., Bisceglia, K.J., 2016. Emerging investigators series: Sewer surveillance for monitoring antibiotic use and prevalence of antibiotic resistance: Urban sewer epidemiology. Environ. Sci. Water Res. Technol. 2, 788-799. https://doi.org/10.1039/c6ew00158k

Fernández, M.D.B., Torres, C., Poma, H.R., Riviello-López, G., Martínez, L.C., Cisterna, D.M., Rajal, V.B., Nates, S. V., Mbayed, V.A., 2012. Environmental surveillance of norovirus in Argentina revealed distinct viral diversity patterns, seasonality and spatio-temporal diffusion processes. Sci. Total Environ. 437, 262-269. https://doi.org/10.1016/j.scitotenv.2012.08.033

González-Mariño, I., J. A. Baz-Lomba, N. A. Alygizakis, M. J. Andrés-Costa, R. Bade, A. Bannwarth, L., P. Barron, F. Been, L. Benaglia, J. D. Berset, L. Bijlsma, I. Bodík, A. Brenner, A. L. Brock, D. A. Burgard, E. Castrignanò, A. Celma, C. E. Christophoridis, A. Covaci, O. Delémont, P. de Voogt, D. A. Devault, M. J. Dias, E. Emke, P. Esseiva, D. Fatta-Kassinos, G. Fedorova, K. Fytianos, C. Gerber, R. Grabic, E. Gracia-Lor, S. Grüner, T. Gunnar, E. Hapeshi, E. Heath, B. Helm, F. Hernández, A. Kankaanpaa, S. Karolak, B. Kasprzyk-Hordern, I. KrizmanMatasic, F. Y. Lai, W. Lechowicz, A. Lopes, M. López de Alda, E. López-García, A. S. C. Löve, N. Mastroianni, G. L. McEneff, R. Montes, K. Munro, T. Nefau, H. Oberacher, J. W. O'Brien, R. Oertel, K. Olafsdottir, Y. Picó, B. G. Plósz, F. Polesel, C. Postigo, J. B. Quintana, P. Ramin, M. J. Reid, J. Rice, R. Rodil, N. Salgueiro-González, S. Schubert, I. Senta, S. M. Simões, M. M. Sremacki, K. Styszko, S. Terzic, N. S. Thomaidis, K. V. Thomas, B. J. Tscharke, R. Udrisard, A. L. N. van Nuijs, V. Yargeau, E. Zuccato, S. Castiglioni and C. Ort (2020). Spatio-temporal assessment of illicit drug use at large scale: evidence from 7 years of international wastewater monitoring. Addiction 115(1), 109-120. https://doi.org/10.1111/add.14767 Gouliouris, T., Raven, K.E., Moradigaravand, D., Ludden, C., Coll, F., Blane, B., Naydenova, P., Horner, C., Brown, N.M., Corander, J., Limmathurotsakul, D., Parkhill, J., Peacock, S.J., 2019. Detection of vancomycin-resistant Enterococcus faecium hospital-adapted lineages in municipal wastewater treatment plants indicates widespread distribution and release into the environment. Genome Res. 29, 626-634. 
593 Guo, B., Liu, C., Gibson, C., Frigon, D., 2019. Wastewater microbial community structure and

594

595

596

597

598

599

600

601

602

603

604

605

606

607

608

609

610

611

612

613

614

615

616

617

618

619

620

621

622

623

624

625

626

627

628

629

630 functional traits change over short timescales. Sci. Total Environ.

https://doi.org/10.1016/j.scitotenv.2019.01.207

Gweon, H.S., Shaw, L.P., Swann, J., De Maio, N., Abuoun, M., Niehus, R., Hubbard, A.T.M., Bowes, M.J., Bailey, M.J., Peto, T.E.A., Hoosdally, S.J., Walker, A.S., Sebra, R.P., Crook, D.W., Anjum, M.F., Read, D.S., Stoesser, N., 2019. The impact of sequencing depth on the inferred taxonomic composition and AMR gene content of metagenomic samples. Environ.

Microbiomes. https://doi.org/10.1186/s40793-019-0347-1

Haghi, F., Shirmohammadlou, N., Bagheri, R., Jamali, S., Zeighami, H., 2019. High frequency of vancomycin-resistant enterococci in sewage and fecal samples of healthy carriers. Open Biotechnol. J. 13, 1-5. https://doi.org/10.2174/1874070701913010001

Hay, S.I., Rao, P.C., Dolecek, C., Day, N.P.J., Stergachis, A., Lopez, A.D., Murray, C.J.L., 2018. Measuring and mapping the global burden of antimicrobial resistance. BMC Med. 16, 1-3. https://doi.org/10.1186/s12916-018-1073-z

Hendriksen, R.S., Lukjancenko, O., Munk, P., Hjelms $\varnothing$, M.H., Verani, J.R., Ng'eno, E., Bigogo, G., Kiplangat, S., Oumar, T., Bergmark, L., Röder, T., Neatherlin, J.C., Clayton, O., Hald, T., Karlsmose, S., Pamp, S.J., Fields, B., Montgomery, J.M., Aarestrup, F.M., 2019a. Pathogen surveillance in the informal settlement, Kibera, Kenya, using a metagenomics approach. PLoS One 14, e0222531. https://doi.org/10.1371/journal.pone.0222531

Hendriksen, R.S., Munk, P., Njage, P., van Bunnik, B., McNally, L., Lukjancenko, O., Roder, T., Nieuwenhuijse, D., Pedersen, S.K., Kjeldgaard, J., Kaas, R.S., Clausen, P.T.L.C., Vogt, J.K., Leekitcharoenphon, P., van de Schans, M.G.M., Zuidema, T., de Roda Husman, A.M., Rasmussen, S., Petersen, B., consortium, G.S.S. project, Amid, C., Cochrane, G., SicheritzPonten, T., Schmitt, H., Alvarez, J.R.M., Aidara-Kane, A., Pamp, S.J., Lund, O., Hald, T., Woolhouse, M., Koopmans, M.P., Vigre, H., Petersen, T.N., Aarestrup, F.M., 2019b. Global monitoring of antimicrobial resistance based on metagenomics analyses of urban sewage. Nat. Commun. 10, 1124. https://doi.org/https://dx.doi.org/10.1038/s41467-019-08853-3

Higgins, J.P.T., Altman, D.G., Gøtzsche, P.C., Jüni, P., Moher, D., Oxman, A.D., Savović, J., Schulz, K.F., Weeks, L., Sterne, J.A.C., 2011. The Cochrane Collaboration's tool for assessing risk of bias in randomised trials. BMJ. https://doi.org/10.1136/bmj.d5928

Huijbers, P.M.C., Larsson, D.G.J., Flach, C.F., 2020. Surveillance of antibiotic resistant Escherichia coli in human populations through urban wastewater in ten European countries. Environ. Pollut. 261, 114200.

https://doi.org/http://dx.doi.org/10.1016/j.envpol.2020.114200

Hutinel, M., Huijbers, P.M.C., Fick, J., Ahren, C., Larsson, D.G.J., Flach, C.-F.F., 2019. Population-level surveillance of antibiotic resistance in Escherichia coli through sewage analysis. Euro Surveill. 24, 1800497. https://doi.org/http://dx.doi.org/10.2807/15607917.ES.2019.24.37.1800497 
Jakobsen, L., Sandvang, D., Hansen, L.H., Bagger-Skjøt, L., Westh, H., Jørgensen, C., Hansen, D.S., Pedersen, B.M., Monnet, D.L., Frimodt-Møller, N., Sørensen, S.J., Hammerum, A.M., 2008. Characterisation, dissemination and persistence of gentamicin resistant Escherichia coli from a Danish university hospital to the wastewater environment. Environ. Int. 34, 108115. https://doi.org/10.1016/j.envint.2007.07.011

Jørgensen, S.B., Søraas, A. V, Arnesen, L.S., Leegaard, T.M., Sundsfjord, A., Jenum, P.A., 2017. A comparison of extended spectrum beta-lactamase producing Escherichia coli from clinical, recreational water and wastewater samples associated in time and location. PLoS One 12, e0186576. https://doi.org/http://dx.doi.org/10.1371/journal.pone.0186576

Karkman, A., Berglund, F., Flach, C.-F., Kristiansson, E., Larsson, D.G.J., 2020. Predicting clinical resistance prevalence using sewage metagenomic data. Commun. Biol. 3, 711. https://doi.org/http://dx.doi.org/10.1038/s42003-020-01439-6

Knudsen, B., Bergmark, L., Munk, P., Lukjancenko, O., Priemé, A., Aarestrup, F. and Pamp, S., 2016. Impact of Sample Type and DNA Isolation Procedure on Genomic Inference of Microbiome Composition. mSystems, 1(5). https://doi.org/10.1128/mSystems.00095-16

Lal Gupta, C., Kumar Tiwari, R. and Cytryn, E., 2020. Platforms for elucidating antibiotic resistance in single genomes and complex metagenomes. Environment International, 138, 105667.

Landis, J.R., Koch, G.G., 1977. The Measurement of Observer Agreement for Categorical Data. Biometrics. https://doi.org/10.2307/2529310

Larson, R., Berman, O. and Nourinejad, M., 2020. Sampling Manholes to Home in on SARSCoV-2 Infections. SSRN Electronic Journal. https://doi.org/10.1371/journal.pone.0240007

Meir-Gruber, L., Manor, Y., Gefen-Halevi, S., Hindiyeh, M.Y., Mileguir, F., Azar, R., Smollan, G., Belausov, N., Rahav, G., Shamiss, A., Mendelson, E., Keller, N., 2016. Population Screening Using Sewage Reveals Pan-Resistant Bacteria in Hospital and Community Samples. PLoS One, [Erratum in: PLoS One. 2017 Jan 12;12 (1):e0170538; PMID: 28081232 [https://www.ncbi.nlm.nih.gov/pubmed/28081232]] 11, e0164873. https://doi.org/https://dx.doi.org/10.1371/journal.pone.0164873

Michael-Kordatou, I., Karaolia, P. and Fatta-Kassinos, D., 2020. Sewage analysis as a tool for the COVID-19 pandemic response and management: the urgent need for optimised protocols for SARS-CoV-2 detection and quantification. Journal of Environmental Chemical Engineering, 8(5), 104306. https://doi.org/10.1016/j.jece.2020.104306

Newton, R.J., McLellan, S.L., Dila, D.K., Vineis, J.H., Morrison, H.G., Murat Eren, A., Sogin, M.L., 2015. Sewage reflects the microbiomes of human populations. MBio 6, 1-9. https://doi.org/10.1128/mBio.02574-14

O’Neill, J., 2016. Tackling Drug-Resistant Infections Globally: Final Report and Recommendations. https://amrreview.org/sites/default/files/160525_Final\%20paper_with\%20cover.pdf 
Ogilvie, D., Fayter, D., Petticrew, M., Sowden, A., Thomas, S., Whitehead, M., Worthy, G., 2008. The harvest plot: A method for synthesising evidence about the differential effects of interventions. BMC Med. Res. Methodol. https://doi.org/10.1186/1471-2288-8-8

Pärnänen, K.M.M., Narciso-Da-Rocha, C., Kneis, D., Berendonk, T.U., Cacace, D., Do, T.T., Elpers, C., Fatta-Kassinos, D., Henriques, I., Jaeger, T., Karkman, A., Martinez, J.L., Michael, S.G., Michael-Kordatou, I., O’Sullivan, K., Rodriguez-Mozaz, S., Schwartz, T., Sheng, H., Sørum, H., Stedtfeld, R.D., Tiedje, J.M., Giustina, S.V. Della, Walsh, F., Vaz-Moreira, I., Virta, M., Manaia, C.M., 2019. Antibiotic resistance in European wastewater treatment plants mirrors the pattern of clinical antibiotic resistance prevalence. Sci. Adv. 5. https://doi.org/10.1126/sciadv.aau9124

Pehrsson, E.C., Tsukayama, P., Patel, S., Mejia-Bautista, M., Sosa-Soto, G., Navarrete, K.M., Calderon, M., Cabrera, L., Hoyos-Arango, W., Bertoli, M.T., Berg, D.E., Gilman, R.H., Dantas, G., 2016. Interconnected microbiomes and resistomes in low-income human habitats. Nature 533, 212-216. https://doi.org/https://dx.doi.org/10.1038/nature17672

Pignato, S., Coniglio, M.A., Faro, G., Lefevre, M., Weill, F.X., Giammanco, G., 2010. Molecular epidemiology of ampicillin resistance in Salmonella spp. and Escherichia coli from wastewater and clinical specimens. Foodborne Pathog. Dis. 7, 945-951. https://doi.org/http://dx.doi.org/10.1089/fpd.2009.0504

Pot, M., Guyomard-Rabenirina, S., Couvin, D., Ducat, C., Enouf, V., Ferdinand, S., Gruel, G., Malpote, E., Talarmin, A., Breurec, S., Reynaud, Y., 2020. Dissemination of ESBL-producing Enterobacter cloacae complex from a hospital to the nearby environment in Guadeloupe (French West Indies): ST114 lineage coding for successful IncHI2/ST1 plasmid. Antimicrob. Agents Chemother. https://doi.org/https://dx.doi.org/10.1128/AAC.02146-20

Poulsen, CS., Kaas, RS., Aarestrup, FM., Pamp, SJ., 2021. Standard Sample Storage Conditions Impact on Inferred Microbiome Composition and Antimicrobial Resistance Patterns. bioRxiv. 2021.05.24.445395. https://doi.org/10.1101/2021.05.24.445395

Rahimi, F., Bouzari, M., 2015. Biochemical fingerprinting of methicillin-resistant staphylococcus aureus isolated from sewage and hospital in Iran. Jundishapur J. Microbiol. 8, 1-5. https://doi.org/10.5812/jjm.19760v2

Raven, K.E., Ludden, C., Gouliouris, T., Blane, B., Naydenova, P., Brown, N.M., Parkhill, J., Peacock, S.J., 2019. Genomic surveillance of Escherichia coli in municipal wastewater treatment plants as an indicator of clinically relevant pathogens and their resistance genes. Microb. genomics 5. https://doi.org/https://dx.doi.org/10.1099/mgen.0.000267

Reinthaler, F.F., Galler, H., Feierl, G., Haas, D., Leitner, E., Mascher, F., Melkes, A., Posch, J., Pertschy, B., Winter, I., Himmel, W., Marth, E., Zarfel, G., 2013. Resistance patterns of Escherichia coli isolated from sewage sludge in comparison with those isolated from human patients in 2000 and 2009. J. Water Health 11, 13-20. https://doi.org/10.2166/wh.2012.207 Saifi, M., Pourshafie, M.R., Dallal, M.M.S., Katouli, M., 2009. Clonal groups of high-level gentamicin-resistant Enterococcus faecium isolated from municipal wastewater and clinical 
samples in Tehran, Iran. Lett. Appl. Microbiol. 49, 160-165. https://doi.org/https://dx.doi.org/10.1111/j.1472-765X.2009.02559.x

Shanks, O., Newton, R., Kelty, C., Huse, S., Sogin, M. and McLellan, S., 2013. Comparison of the Microbial Community Structures of Untreated Wastewaters from Different Geographic Locales. Applied and Environmental Microbiology, 79(9), 2906-2913. https://doi.org/10.1128/AEM.03448-12

Shaw, L., Chau, K., Kavanagh, J., AbuOun, M., Stubberfield, E., Gweon, H., Barker, L., Rodger, G., Bowes, M., Hubbard, A., Pickford, H., Swann, J., Gilson, D., Smith, R., Hoosdally, S., Sebra, R., Brett, H., Peto, T., Bailey, M., Crook, D., Read, D., Anjum, M., Walker, A. and Stoesser, N., 2021. Niche and local geography shape the pangenome of wastewater- and livestockassociated Enterobacteriaceae. Science Advances, 7(15), p.eabe3868. https://doi.org/10.1126/sciadv.abe3868

Su, J.-Q., An, X.-L., Li, B., Chen, Q.-L., Gillings, M.R., Chen, H., Zhang, T., Zhu, Y.-G., 2017. Metagenomics of urban sewage identifies an extensively shared antibiotic resistome in China. Microbiome, [Erratum in: Microbiome. 2018 Jul 9;6(1):127; PMID: 29986764 [https://www.ncbi.nlm.nih.gov/pubmed/29986764]] 5, 84. https://doi.org/https://dx.doi.org/10.1186/s40168-017-0298-y

Tacconelli, E., Sifakis, F., Harbarth, S., Schrijver, R., van Mourik, M., Voss, A., Sharland, M., Rajendran, N.B., Rodríguez-Baño, J., Bielicki, J., de Kraker, M., Gandra, S., Gastmeier, P., Gilchrist, K., Gikas, A., Gladstone, B.P., Goossens, H., Jafri, H., Kahlmeter, G., Leus, F., Luxemburger, C., Malhotra-Kumar, S., Marasca, G., McCarthy, M., Navarro, M.D., NuñezNuñez, M., Oualim, A., Price, J., Robert, J., Sommer, H., von Cube, M., Vuong, C., Wiegand, I., Witschi, A.T., Wolkewitz, M., 2018. Surveillance for control of antimicrobial resistance. Lancet Infect. Dis. 18, e99-e106. https://doi.org/10.1016/S1473-3099(17)30485-1

Tong, J., Tang, A., Wang, H., Liu, X., Huang, Z., Wang, Z., Zhang, J., Wei, Y., Su, Y., Zhang, Y., 2019. Microbial community evolution and fate of antibiotic resistance genes along six different full-scale municipal wastewater treatment processes. Bioresour. Technol. https://doi.org/10.1016/j.biortech.2018.10.079

Urase, T., Okazaki, M., Tsutsui, H., 2020. Prevalence of ESBL-producing Escherichia coli and carbapenem-resistant Enterobacteriaceae in treated wastewater: a comparison with nosocomial infection surveillance. J. Water Health 18, 899-910.

https://doi.org/http://dx.doi.org/10.2166/wh.2020.014

WHO, 2019. Global action plan on AMR: Objective 2. https://apps.who.int/iris/bitstream/handle/10665/193736/9789241509763_eng.pdf?seque nce $=1$

WHO, 2018. Global Antimicrobial Resistance Surveillance System (GLASS) Report Early implementation 2017-18. https://apps.who.int/iris/bitstream/handle/10665/279656/9789241515061-eng.pdf?ua=1 
746 Wright, G.D., 2007. The antibiotic resistome: The nexus of chemical and genetic diversity.

747 Nat. Rev. Microbiol. 5, 175-186. https://doi.org/10.1038/nrmicro1614

748 YoungKeun, K., Colque, P., Byfors, S., Giske, C.G., Mollby, R., Kuhn, I., 2015. Surveillance of 749 antimicrobial resistance among Escherichia coli in wastewater in Stockholm during 1 year:

750 does it reflect the resistance trends in the society? Int. J. Antimicrob. Agents 45, 25-32.

751 https://doi.org/http://dx.doi.org/10.1016/j.ijantimicag.2014.09.016

752 Zaheer, R., Cook, S.R., Barbieri, R., Goji, N., Cameron, A., Petkau, A., Polo, R.O., Tymensen, L.,

753 Stamm, C., JiMing, S., Hannon, S., Jones, T., Church, D., Booker, C.W., Amoako, K.,

754 Domselaar, G. van, Read, R.R., McAllister, T.A., 2020. Surveillance of Enterococcus spp.

755 reveals distinct species and antimicrobial resistance diversity across a One-Health

756 continuum. Sci. Rep. 10, 3937. https://doi.org/http://dx.doi.org/10.1038/s41598-020-

$757 \quad 61002-5$

758 Zarfel, G., Feierl, G., Galler, H., Haas, D., Leitner, E., Mascher, F., Melkes, A., Posch, J.,

759 Winter, I., Masoud, L., Grisold, A.J., Marth, E., 2010. Comparison of ESBL genes from

760 extended-spectrum beta-lactamase carrying Escherichia coli from sewage sludge and human

761 urinary tract infection. Clin. Microbiol. Infect., 20th ECCMID. Vienna Austria. 16, S353-S354.

762 https://doi.org/http://dx.doi.org/10.1111/j.1469-0691.2010.03239.x

763 Zhang, L., Cheng, Y., Qian, C., Lu, W., 2020. Bacterial community evolution along full-scale

764 municipal wastewater treatment processes. J. Water Health 18, 665-680.

765 https://doi.org/10.2166/wh.2020.092 